\title{
PLC based Signaling of BRTs
}

\author{
Ashwini Kale \\ Electronics and Telecommunication \\ DYPCOE Ambi
}

\author{
Supriya Bhosale \\ Information Technology \\ DYPCOE Ambi.
}

\begin{abstract}
Signaling of BRTs using PLC is undertaken with a view to make the traffic system of Pune more convenient to the common man, currently or traffic system is based on microcontroller whose operating cost is very high and not user friendly but by using PLC whose initial cost is high but the operating cost is negligible and also the traffic signal also can be centrally controlled by using PLC. With the help of PLC we tried to resolve and synchronize the traffic system by using BRTS in which there is one lane for the public means of transport and other lane is for normal traffic.
\end{abstract}

\section{Keywords}

Traffic Signalling, BRTs, PLC.

\section{INTRODUCTION}

Here we have taken one signal junction i.e. City pride signal. We have observed the traffic system and calculated the time required for any vehicle to clear the traffic at different periods. With the help of data we made few programs in the PLC and found out which one is taking less time to clear the normal traffic and BRTS so that every means of transport would not have to wait for signal to get cleared. Here we have written a code for one signal junction because of limited output but by using larger PLC we can perform every signal.

\section{HISTORY \& BACKGROUND}

Transportation has the ability to provide some powerful benefits to the society. That's why much importance is given to this field. In addition to supporting specialization, transportation provides us with sort of mobility and accessibility we need to live our lives. Generally, there is widely accepted link between economic well-being and good transportation. We must also not forget that fuel is a fast dwindling commodity and the biggest expense for our nation, having cost Rs. 1,50,000 crores last year. Typically, rail based modes such as trams; urban rail (locals) and Metro provide such a service. They are however very expensive and also need a long time to build. Currently, many cities experience significant periods of congestion especially during the morning and evening peaks. The congestion is directly attributable to the poor capacity of the existing roadway network due in part to the inefficient traffic signal system. Public Transport is the most effective means of moving people. By the principle of urban transport policy; mobility should be provided to people $\&$ not to vehicles. A single bus carrying 60 people occupies a fraction of the road space that would be occupied if they all traveled in a car or on 2wheelers. Congestion can thus be reduced if more people use a bus and do not have to use their own vehicles.

\section{BUS RAPID TRANSIT SYSTEM MODEL}

Bus Rapid Transit - BRT.In this Fig 1 BRTS consists of several components designed to function together so as to generate superior services, which are omparable with other mass rapid transit system including metro rail system. Some or all of these elements are integrated to form BRTS, which will ensure fast, reliable, secure, high capacity service, which also has a distinct identity.

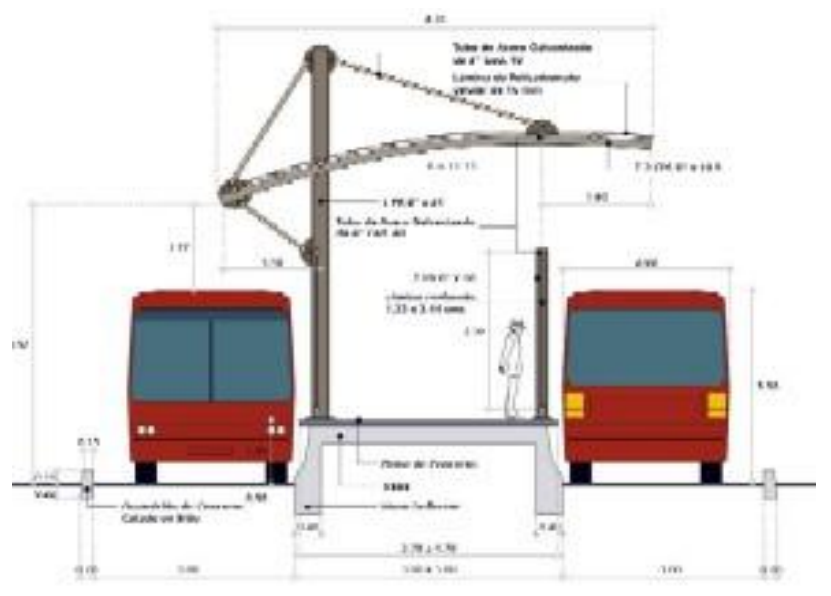

Fig 1: Bus Rapid Transit Model

Vehicular congestion levels on roads will not increase just because one lane has got taken away to the BRTS from otherwise a three lane road. This is so because, by segregating buses from other motorized vehicles the road space will be more efficiently used. In the existing systems, 2-wheelers and rickshaws as well as vendors halt at the bus stops, preventing use of the entire curbside lane effectively. Buses halt away from the kerbed side space at bus stops, which effectively makes buses block the flowing lanes beyond. When a bus in the rear wants to overtake the halted bus at the bus stop, it further blocks additional lane, effectively slowing down the entire traffic if not bringing it down to a halt. The BRTS road design caters to vendors halting at bus stops without blocking in fig 2 flowing traffic and also, the fact that buses are no longer occupying the remaining road space, other vehicles would move with lesser impediments. In fact there will be better flow of traffic.

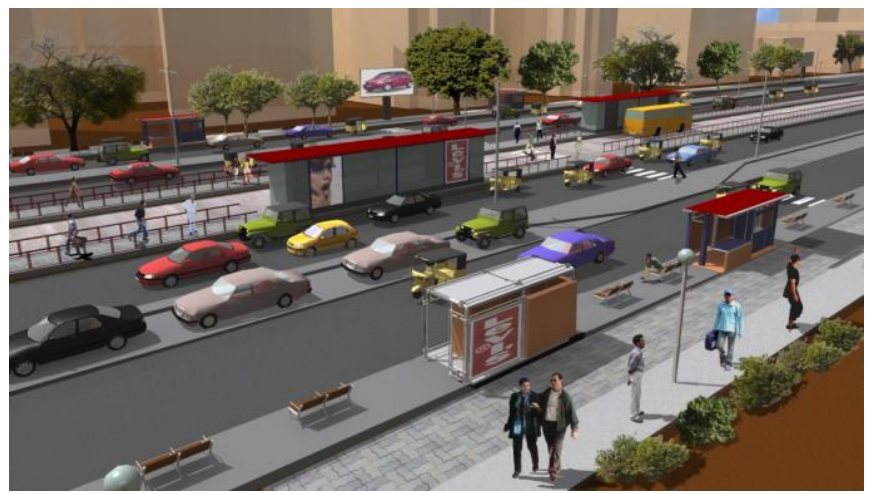

Fig 2: BRTS flow of traffic.

It is important to remember that providing additional space for motorized personal vehicle use will invariably encourage 
more vehicles coming on the roads and congestion catching up in no time. It is an ever insatiate demand. More vehicles on the roads also mean heavy investments needed on parking spaces and trying to provide additional road space. Thus, even by having BRTS, congestion on MV lanes may remain in the long run, however bus lanes will remain congestion free and will prove viable alternative to personal vehicles on the same routes. Also these lanes are available for ambulance, fire brigade and police vehicles providing a congestion free route to them.

\section{There are two types of lanes for BRTS:-}

\begin{tabular}{|c|c|}
\hline SIDE LANE & MEDIAN LANE \\
\hline $\begin{array}{l}\text { Compatible with conventional bus door } \\
\text { configuration on curb side (left side). }\end{array}$ & $\begin{array}{l}\text { Easy to integrate bus flow with other flow } \\
\text { at intersection }\end{array}$ \\
\hline $\begin{array}{l}\text { Easier accessibility from the pedestrian } \\
\text { pathway. }\end{array}$ & $\begin{array}{l}\text { Optimum road width for both direction } \\
\text { movements. }\end{array}$ \\
\hline $\begin{array}{l}\text { Total road width occupied for bus lane is } \\
\text { double. }\end{array}$ & $\begin{array}{l}\text { Infrastucture created can be utilized even } \\
\text { if BRTS withdrawn. }\end{array}$ \\
\hline Capacity will remain under utilized. & $\begin{array}{l}\text { Traditional bus door configuration on left } \\
\text { side of travel can be retained by providing } \\
\text { bus stops on left side. }\end{array}$ \\
\hline $\begin{array}{l}\text { Cost intensive treatment at junctions would } \\
\text { have to be carried out, as free left turn for } \\
\text { regular traffic would be cut off. }\end{array}$ & $\begin{array}{l}\text { Slight diversion to other traffic when a } \\
\text { bulge is provided to accommodate the } \\
\text { bus stops. }\end{array}$ \\
\hline Example: Quito & Examples: Boqotá, Curitiba, Cambridue \\
\hline
\end{tabular}

Advantages of central lane of BRTS over side lane:

There are a lot of side lanes on our roads and vehicles entering or exiting these lanes would have to "puncture" the BRT lane, which is not desirable. Left turning traffic would also impede the movement of buses in the lane. While the same if true of right turning traffic for the central lane, this is overcome by the use of signal timing at each intersection. Central lanes however give rise to an interesting question. How do commuters access the buses? The answer is bus shelters in the centre of the road! This seems like a very strange solution, but it is one that has worked in all such BRT systems in the world. The bus shelters are placed just before each intersection. Commuters must use the pedestrian crossing to get to and from the bus shelters.

The idea of a dedicated lane for buses, while welcome to current and potential BRT users must surely be welcome, what happens to the other traffic? Currently buses stop at the side of the road

But typically cross to the centre while traveling. This impedes the flow of the rest of the traffic. Central dedicated lane for buses, will in fact allow for a smoother flow for the rest of the vehicles. Additionally, BRT in India must include footpaths and cycle tracks. This makes the road safe for pedestrians and cyclists and also removes slow-moving traffic from the main road carriageway, further improving the flow of traffic. Many of our roads are also not fully utilized. You will often see "dead space" on the left side, where vehicles are haphazardly parked, debris is lying around etc. Even with a 3-lane width, only $1 \frac{1 / 2}{2}$ or 2 lanes of moving traffic is possible. BRT requires the full use of the road, thus allowing this "dead space" to be reclaimed. Central lanes and central bus shelters clearly require an added effort to impose discipline at the intersections. Given the urrent situation, this in itself will be much welcomed by Pune.

\section{ELEMENTS OF BUS RAPID TRANSMIT SYSTEM}

Transportation has the ability to provide some powerful benefits to the society. That's why much importance is given to this field. In addition to supporting specialization, transportation provides us with sort of mobility and accessibility we need to live our lives. Generally, there is widely accepted link between economic well-being and good transportation. We must also not forget that fuel is a fast dwindling commodity and the biggest expense for our nation, having cost Rs 1,50,000 crores last year. Typically, rail based modes such as trams; urban rail (locals) and Metro provide such a service. They are however very expensive and also need a long time to build.

The great hope for all urban traffic nightmares is public transport, but on this front too there is little cheer. The PMT currently operates 818 buses operating 63.4 million $\mathrm{km}$ of route and transports approximately 0.23 billion passengers per annum. Bus fares are charged on the basis of $\mathrm{km}$ traveled. The Pune Municipal Transport (PMT) is in a sorry condition, with 50 per cent of the buses are more than 10 years old, resulting in nearly 15 per cent of the fleet being inoperable on any given day. To make matters worse, infrequent service in many areas, bad maintenance of the buses, and the citizenunfriendly image of the PMT all steer away many residents, who have turned - with no alternative - to private transport. Around one lakh vehicles have been registered annually for the last few years; the city, with a population of around 30 lakhs, has nearly 14 lakh vehicles, 70 per cent of which are two-wheelers. As private vehicle ownership continues to rise, and with no significant alternatives for public transport, the already weak infrastructure deteriorates a little each day. However, in the current scenario it is the road congestion that is the cause of low speeds, high fuel consumption and adherence to buses wanting in comfort

\section{BASIC REQUIREMENTS OF THE SYSTEM-}

Our project is Synchronization of Traffic signal using PLC in which the programming in PLC is the foundation of this project for which we should have proper knowledge for PLC programming. Due to this most important requirement we have taken PLC programming training under the guidance of Mr. Sachin. K. Kadam. To start with this project we need the map of Pune City from which we have selected city pride (Satara road) circle due to the limited output of the PLC. In that circle we watched the traffic for next 7 days and recorded all the data such as how much time is taking for BRTS and normal traffic to get clear at different time? From data we calculated best option and time limit so that the there should be minimum stoppage at every signal. We did programming in PLC from that data. After the programming is over we have to show it on hardware for hardware part we require LED's, Relays, Plywood, wires, Steel rod, Casing, PLC kit etc.

\section{ALGORITHM}

\section{START}

2. Turn on lights G1, G3, R2, and R4 for 15 seconds.

3. Turn on yellow lights Y1, Y3 for 5 seconds.

4. Turn on lights G2, G4, R1, and R3 for 15 seconds.

5. Turn on yellow lights Y2, Y4 for 5 seconds.

6. Go to step 1 if no BRT is sensed else go to step7. 
7. Turn on yellow lights $\mathrm{Y} 1, \mathrm{Y} 2, \mathrm{Y} 3, \mathrm{Y} 4$ for 5 seconds.

8. If I3 or I5 are on, Turn on timer T5 for 5 seconds.

9. After time T5 turn on G5, G3, R1, R2, R3, and R4.

10. When I4 or I6 are on then go to step 1.

11. STOP.

\section{DETAILED WORKING}

BRTs is considered as revolution in the world of transportation. Commuters can travel quickly to their destination.PUNE has privilege of becoming first city in INDIA to have BRTs. It covers in all 21 bus stops on Hadapsar-Katraj Route via Swargate covering $15 \mathrm{~km}$ and 28 signals.

The reliability of BRTs can be observed by the fact that earlier PMT busses use to take $1 \mathrm{hr}$ and 30 minutes but after induction of BRTs, time has been drastically reduced to 45 minutes to reach katraj from Hadapsar. Moreover if Synchronization of BRTS route is done the time taken would be further be reduced to 30 minutes. BRTs services are available from 5a.m. to 11 p.m, comprising of 18 hours of continuous service in a day and running 15 hour a day halting $2 \mathrm{hr} 30$ minutes at katraj and Hadapsar bus depot. In all about 15 trips by a single bus, after implementing synchronization single bus would be able to make 25 trips increase in the usability of a bus will be $66 \%$ time saved is $25 \mathrm{~min}$ during a trip.

Layout: Here we are considering Aranyeshwar chowk which is in proximity of CITY PRIDE PUNE-SATARA road. While heading towards katraj from Swargate this chowk comes after Bhapkar Gultekdi corner and before Big Bazaar bus stop we are implementing 4 sensors:

Sensor 1 is located $100 \mathrm{~m}$ prior to Aranyeshwar bus stop towards City pride.

Sensor2 is located prior to Aranyeshwar bus stop towards Big Bazaar.

Sensor 3 and sensor 4 is located $2 \mathrm{~m}$ away from Aranyeshwar chowk and in BRT lane in opposite direction.

Working of the Sensor $1 \&$ sensor 3 are placed $100 \mathrm{~m}$ prior to two Bus Stop. These Sensors are basically proximity/Photo sensor. Prior to the sensing of the Bus traffic signal will follow its normal sequence.

1. After 10 seconds and yellow will remain $\mathrm{ON}$ for 5 seconds.

2. After yellow light, red light will $\mathrm{ON}$ and green light of 2nd signal will start.

3. When sensor 1 or 3 gets detected the BRTs signal will become green and other signal will remain red.

4. As soon as BRTs get $\mathrm{s}$ detected by sensor 2 and sensor 4 after crossing the chowk, BRTs signal will turn red and four-way traffic will follow, the sequence will start with turning the signals green for the traffic coming from 2 nd signal. While other signals will remain red for 10 seconds.

5. After 10 seconds green will turn Yellow.

6. Now the signal for the traffic coming from 3rd signal will turn green, Other Signals will be red.

7. After 10 seconds green will turn yellow.
8. Now traffic signal for the traffic coming from 4 th signal will turn green, Other signal will be red.

9. After 10 seconds, green will turn Yellow. Finally again traffic signal for the traffic coming from $1 \mathrm{st}$ signals will turn Green, other will be red.

10. During the period 11p.m-7a.m traffic rush is low hence all the signals are kept yellow in blinking mode

\section{ADVANTAGES OF BRTS}

1. .Improves safety.

2. .Maximizes the Ridership; present and the potential.

3. .Have citywide impacts.

4. Serve the needs of the poor.

5. .Provide opportunities for Transit-Oriented Development/ Promote Compact City.

6. Integrate with other modes and thus provide greater accessibility to amenities and Opportunities for mobility.

7. Considerable time savings .

\section{AREAS OF IMPLEMENATATION}

\section{BRTS on NH-4 Katraj-Wakad route-}

The population of Pune city is increasing day by day. In 2005, it has crossed 33 lacs. As central part of city is saturated, Pune is expanding at outskirt areas like Wakad, Bavdhan, Warje, Katraj etc. From Auto city, Pune has slightly shifts towards IT city. Many companies provide private bus service to their employees. But these buses cause traffic congestion at city roads. To reach to their destination at Hijewadi, these buses follow the above route. In addition to above, many people prefer to use the highway for time-saving and to avoid congestion at city roads. But as number of vehicles increase, number of accidents also increases. To eliminate these drawbacks, BRTS could be the best substitute for said route.

There is a need of BRT route on Bangalore-Mumbai National Highway 4 from Katraj-Warje-Chandani Chowk-Wakad, which is most rapidly developing areas of Pune city. Many working people, especially related to IT companies at Hijewadi use this road for their car journey. This Road also provides easy access to suburban areas like Ambegaon, Narhe, Wadgaon, Hingne, Warje, Kothrud, and Bavdhan etc. which are developing speedily. But there are significant cases of accidents with high fatality rate in Pune city. The PMT bus fleet is old and limited which cannot provide good service on this route. Pollution and congestion are the major problems related with city buses.

To overcome all these problems, we strongly recommend BRTS on above road because; it could be implemented quickly and at less costs. It could improve mobility options of large segments of people. It will reduce the air and noise pollution to great extent with considerable time savings.

\section{CONCLUSION}

Implementation of BRTS will leads to following-

1. Reduction in turn-around time leading to increased vehicle utilization.

2. Size of operations increase.

3. Large size operations mean mobility improvement to many.

4. Extensions to the network possible. 
5. Flexible Operations.

6. Possible to operate BRTS as independent operation.

7. Private participation.

8. Monitoring and regulating of services become less complex.

\section{REFERENCES}

[1] Diaz, R. B., \& Hinebaugh, D. (Eds.), (2009). Characteristics of Bus Rapid Transit for decision-making (CBRT). National Bus Rapid Transit Institute for the Federal Transit Administration, Document FTA-FL26e7109.2009.1.

[2] Finn, B., Heddebaut, O., Kerkhof, A., Rambaud, F., Sbert-Lozano, O., \& Soulas, C. (Eds.), (2011). Buses with high level service: Fundamental characteristics and recommendations for design making and research, final report Oct 2011.

[3] Munoz, J. C., \& Hidalgo, D. (2011). Bus rapid transit as part of enhanced service provision. Thredbo 12 conference on competition and ownership issues in land passenger transport, Durban, South Africa, September, $11 \mathrm{e} 15,2011$.

[4] Levinson, H., Zimmerman, S., Clinger, J., Rutherford, S., Smith, R. L., Cranknell, J., et al. (2003). Transit Cooperative Research Program e Report 90. Bus rapid transit e Volume 1: Case studies in bus rapid transit, Vol I. Washington, D.C: Transportation Research Board, National Academies.

[5] U.S. General Accounting Office report: "Bus Rapid Transit Shows Promise"

[6] Public Transport International: "BRT in China; James Wang, China"(PDF) buspriority.org

[7] NYC Bus Rapid Transit Study BRT in China (PDF) Transportation Research Board: Bus Rapid Transit, Volume 1: Case Studies in Bus Rapid Transit Transportation Research Board: Bus Rapid Transit, Volume 2: Implementation 